\title{
A CLINICAL STUDY OF CLONIDINE AS AN ADJUVANT TO INTRATHECAL 0.5\% HYPERBARIC BUPIVACAINE FOR TIBIAL INTRAMEDULLARY NAILING
}

\author{
Madhava Reddy R', Tejal N. Jivrajani², Rosalyn Fiona Cyril ${ }^{3}$
}

${ }_{1}^{1}$ Professor, Department of Anaesthesia, Kempegowda Institute of Medical Sciences, Bangalore.

${ }^{2}$ Senior Resident, Department of Anaesthesia, St. John's Medical College, Bangalore.

3 Junior Resident, Department of Anaesthesia, Kempegowda Institute of Medical Sciences, Bangalore.

ABSTRACT: BACKGROUND: Postoperative pain may produce a range of detrimental acute and chronic effects. Subarachnoid block provided by Bupivacaine alone may be too short for the planned postoperative analgesia. Intrathecal Clonidine in varying dosages has been used as an additive to local anaesthetics to prolong the duration of subarachnoid block.

AIM: Studies using lower doses of Clonidine i.e. $<1 \mathrm{mcg} / \mathrm{kg}$ are minimal. This study was conducted to evaluate the safety and efficacy of two different doses of intrathecal Clonidine as an adjuvant to $0.5 \%$ hyperbaric Bupivacaine to prolong the duration of analgesia.

METHODS: In this randomized clinical study 60 patients scheduled for Tibial intramedullary nailing were divided into two groups. Group 1 received 0.5\% Hyperbaric Bupivacaine $2.5 \mathrm{ml}$ with $0.5 \mathrm{ml}$ of $0.5 \mathrm{mcg} / \mathrm{kg}$ Clonidine and Group 2 received $0.5 \%$ Hyperbaric Bupivacaine $2.5 \mathrm{ml}$ with $0.5 \mathrm{ml}$ of $1 \mathrm{mcg} / \mathrm{kg}$ Clonidine. Onset of sensory and motor block, maximum level of sensory blockade attained and time for the same were recorded. Sedation score was noted. Vital parameters were recorded preoperatively. Duration of analgesia and time to recovery from motor and sensory blockade were recorded .Patients were observed for any adverse events and treated accordingly.

RESULTS: The onset of sensory block in group 1 and group 2 was $2.17 \pm 0.36$ min and $1.58 \pm 0.35$ min respectively. Time to onset of motor block was $3.05 \pm 0.36 \mathrm{~min}$ in group 1 and $2.33 \pm 0.50 \mathrm{~min}$ in group 2. Total duration of sensory block was noted to be $258.17 \pm 10.21 \mathrm{~min}$ and $289.33 \pm 15.24 \mathrm{~min}$ in group 1 and group 2 respectively. Total duration of motor block in group 1 and 2 were $228.83 \pm 10.96 \mathrm{~min}$ and $260.33 \pm 14.74 \mathrm{~min}$. The duration of analgesia was $306.33 \pm 18.24 \mathrm{~min}$ in group 1 and $351.00 \pm 15.83 \mathrm{~min}$ in group 2. Hemodynamically no statistically significant variations were noted. Sedations scores were similar. No other untoward complications were observed.

CONCLUSION: Both the doses of Clonidine as an adjuvant prolong the duration of analgesia of 0.5\% hyperbaric Bupivacaine in the study groups. Though the difference in duration of analgesia is statistically significant, clinically it's about 45 minutes only. No significant differences were noted pertaining to hemodynamic changes and complications. $0.5 \mathrm{mcg} / \mathrm{kg}$ of clonidine is almost as effective as $1 \mathrm{mcg} / \mathrm{kg}$ of clonidine in the patients studied.

KEYWORDS: Intrathecal Block; Bupivacaine; Clonidine; Analgesia.

HOW TO CITE THIS ARTICLE: Madhava Reddy R, Tejal N. Jivrajani, Rosalyn Fiona Cyril. "A Clinical Study of Clonidine as an Adjuvant to Intrathecal 0.5\% Hyperbaric Bupivacaine for Tibial Intramedullary Nailing". Journal of Evolution of Medical and Dental Sciences 2015; Vol. 4, Issue 89, November 05; Page: 15422-15425, DOI: 10.14260/jemds/2015/2200.

INTRODUCTION: Intrathecal block is the most commonly used technique for lower limb surgeries. This technique is simple to perform and the onset of anaesthesia is rapid, allowing the surgical incision to be made sooner and also providing good sensory block, motor block with better analgesia that can be extended to post-operative period. Different local anaesthetics are used for subarachnoid block but bupivacaine gained popularity due to its longer action and better motor blockade compared to other local anaesthetics. ${ }^{1}$

The analgesia can be prolonged with an epidural catheter placement, but lesser motor blockade and cost effectiveness are the drawbacks of epidurals. Since cost effectiveness is the main concern for most of the patients in our institute who come from a rural background the other alternative to prolong the duration of analgesia of a subarachnoid block is to add adjuvants to the local

Financial or Other, Competing Interest: None Submission 10-10-2015, Peer Review 11-10-2015,

Acceptance 21-10-2015, Published 04-11-2015.

Corresponding Author:

Dr. Tejal N Jirajani,

155/9/2, First floor, First Stage, $5^{\text {th }}$ Cross,

Okalopuram (Opposite Jain Temple), Bangalore-560021.

E-mail: tejaljivrajani86@gmail.com

DOI:10.14260/jemds/2015/2200 anaesthetics. Different adjuvants are being used to improve the quality and duration of analgesia with various results. ${ }^{2,3}$ Clonidine, an alpha2 agonist, when used as an adjuvant potentiates the effect of local anaesthetics and allows a decrease in their required doses. ${ }^{4-7}$ It is also known to produce analgesia of variable intensity and duration, which is dose dependent.8,9 Clonidine has been used in different dosages from $1 \mathrm{mcg} / \mathrm{kg}$ to $3 \mathrm{mcg} / \mathrm{kg}$ intrathecally. ${ }^{6,10}$ Some have used even upto $450 \mathrm{mcg}$. However, in the dose range of $150-450 \mathrm{mcg}$, Clonidine produces clinically significant side effects like, marked sedation. ${ }^{11}$ and hemodynamic changes. ${ }^{6}$ Hence, to achieve the required postoperative analgesia with minimal side effects, a true alternative is to reduce the dosage of the drugs.

In literature, studies using smaller doses of Clonidine i.e. $<1 \mathrm{mcg} / \mathrm{kg}$ are minimal. So in our study, we wanted to assess the safety, efficacy and duration of analgesia of lower doses of Clonidine as an adjuvant to Bupivacaine for subarachnoid block. Hence, we compared $0.5 \mathrm{mcg} / \mathrm{kg}$ and $1 \mathrm{mcg} / \mathrm{kg}$ of Clonidine as an adjuvant to $0.5 \%$ hyperbaric Bupivacaine in patients undergoing tibial intramedullary nailing.

METHODS: This comparative clinical study was conducted between December 2012 to September 2014, after obtaining the institution Ethics Committee clearance. 60 patients of either sex aged 18- 50 years and ASA status 1 or 2 posted for tibial 
intramedullary nailing under intrathecal block were included in our study. Patients with ASA status other than 1 and 2, spinal deformity, neurological ailments, and deranged coagulation profile, history of chronic headache, pregnancy, lactation and refusal of intrathecal block were excluded from the study.

After taking the written informed consent the patients were randomised by a sealed cover method into two groups of 30 each. Group 1 received $0.5 \%$ bupivaciane $2.5 \mathrm{ml}+0.5 \mathrm{ml}$ of $0.5 \mathrm{mcg} / \mathrm{kg}$ of clonidine whereas Group 2 received $0.5 \%$ of bupivacaine $2.5 \mathrm{ml}+0.5 \mathrm{ml}$ of $1 \mathrm{mcg} / \mathrm{kg}$ of clonidine.

Patients were premedicated with alprazolam $0.5 \mathrm{mg}$ the day before and on the day of surgery in the morning. Basal vital parameters like heart rate, blood pressure, Sp02 were recorded. With patient in sitting position, under aseptic precautions lumbar puncture was performed at $\mathrm{L}_{3} \mathrm{~L}_{4}$ or $\mathrm{L}_{4} \mathrm{~L}_{5}$ interspace with a 26G Quincke needle. After free flow of CSF the test drug was deposited intrathecally and the patient was put back to supine position.

Intraoperatively, onset of sensory and motor blockade, maximum level of sensory blockade attained and the time for the same was recorded. $\mathrm{HR}, \mathrm{NIBP}$ and $\mathrm{SpO}_{2}$ were recorded every 2 minutes for the first 20 minutes, every 15 minutes till the end of surgery and every 30 minutes thereafter. Level of sedation, duration of analgesia, sensory, motor blockade was noted. Adverse events like nausea, vomiting, shivering, postdural puncture headache etc were also noted and treated accordingly. Rescue analgesic, Inj. Diclofenac $75 \mathrm{mg}$ IV infusion was administered when the patient first complained of pain.

In ours study onset of sensory blockade is the time taken from deposition of study drug till the patient does not feel the pin prick at L1 level. Time for maximum sensory blockade is defined as the time taken from deposition of the study drug to the maximum sensory blockade attained. Onset of motor blockade is defined as time taken from deposition of the study drug till the patient develops modified Bromage scale Grade 1 motor blockade.

Time for maximum motor blockade is defined as the time taken from deposition of the study drug to maximum motor blockade attained. Duration of motor block is defined as the time taken from onset of motor block till the patient attains complete motor recovery/recovery to Bromage Grade 0. Duration of sensory block is defined as the time taken from the onset of sensory block till the patients recovers pin prick at $\mathrm{S} 1$ dermatome.

Duration of analgesia is defined as the time taken from onset of sensory blockade till the patient complains of pain at the site of surgery. Hypotension is defined as fall in Mean arterial blood pressure by $\geq 30 \%$ of basal values. Bradycardia is defined as a fall in the heart rate by $\geq 20 \%$ of the basal values. Sensory block was assessed by pin prick method, motor block by modified Bromage scale and level of sedation by five point sedation scale. Statistical analysis was done by using student $\mathrm{T}$ test and chi-square test

RESULTS: There was no statistically significant difference between the two groups in respect to demographic profile (Table 1).Observations regarding sensory and motor blockade are shown in Table 2.The onset of sensory block in Group 1 and Group 2 was $2.17 \pm 0.36 \mathrm{~min}$ and $1.58 \pm 0.35 \mathrm{~min}$ respectively. Time to onset of motor block was $3.05 \pm 0.36$ min in Group 1 and
$2.33 \pm 0.50 \mathrm{~min}$ in Group 2. Total duration of sensory block was noted to be $258.17 \pm 10.21 \mathrm{~min}$ and $289.33 \pm 15.24 \mathrm{~min}$ in Group 1 and Group 2 respectively.

Total duration of motor block in Group 1 and 2 were $228.83 \pm 10.96 \mathrm{~min}$ and $260.33 \pm 14.74 \mathrm{~min}$. The duration of analgesia was $306.33 \pm 18.24 \mathrm{~min}$ in Group 1 and $351.00 \pm 15.83$ min in Group 2 which is statistically significant (Table 3). Intraoperatively there was a minimal fall in the blood pressures in both the groups but defined hypotension occurred in only 3.3\% patients in Group 1 and 6.7\% patients in Group 2(Fig. 1). No significant variations in the heart rate (Fig. 2) and SPO2 were noted between the two groups. Sedations scores were similar in both the groups (Table 4). No other untoward complications were observed

DISCUSSION: Subarachnoid block is currently the most widespread and popular anaesthetic technique in clinical practice. To address the problem of limited duration of action of local anaesthetics and to improve the quality of analgesia both intraoperatively and postoperatively, many additives are being used in regional anaesthesia.

Among the alpha 2 agonist clonidine is widely used as an adjuvant to enhance the action of local anaesthetics. Its analgesic effect following intrathecal administration is mediated spinally through activation of post synaptic alpha 2 receptors in substantia gelatinosa of spinal cord and it works by blocking the conduction of $\mathrm{C}$ and $\mathrm{A}$ delta fibres, increase potassium conductance in isolated neurons in vitro and intensifies conduction block of local anaesthetics.

The quality, quantity of analgesia and intensities of complications are dose dependent. L Niemi ${ }^{6}$ observed a prolongation of motor and sensory block and also a longer duration of analgesia with a significant fall in MAP and HR in patients who received $3 \mathrm{mcg} / \mathrm{kg}$ of clonidine as an adjuvant. OlfaKabaachi et al. ${ }^{12}$ in 2002 evaluated the effect of $2 \mathrm{mcg} / \mathrm{kg}$ of Clonidine as adjuvant and found a high incidence of hypotension and bradycardia. Also the same study group observed a prolonged duration of analgesia without any adverse events with $1 \mathrm{mcg} / \mathrm{kg}$ of clonidine in $2007 .{ }^{13}$ Hence, we have chosen to compare two lower doses of Clonidine i.e., $0.5 \mathrm{mcg} / \mathrm{kg}$ and $1 \mathrm{mcg} / \mathrm{kg}$ as adjuvant to $0.5 \%$ hyperbaric Bupivacaine.

Time taken for the onset of action will be shortened when the dose of clonidine is increased. In our study we observed the onset of both sensory and motor block was faster in Group 2 compared to Group 1 which is similar to H.Saxena et al. ${ }^{14}$ who found out that the onset of action was in 37.5 mcg group than in 15 and 30 mcg group. Total duration of motor block in our study was longer in $1 \mathrm{mcg} / \mathrm{kg}$ of clonidine than $0.5 \mathrm{mcg} / \mathrm{kg}$ which is in par with the observations made by Grandhe RP et al. ${ }^{15}$ Whereas Dobrydnjov et al. ${ }^{3}$ did not notice a significant difference in the duration of motor block when the dose of clonidine was doubled, probably this was due to the very low dose of adjuvant use.

Clonidine has a dose dependent duration of analgesia. Filos KS et al. ${ }^{11}$ in their dose response study they used 150, 300 and $400 \mathrm{mcg}$ of clonidine which resulted in enormous increase in the duration of analgesia. In contrast to this we observe only a difference of about 45 minutes between the groups when the dose of clonidine was doubled. This may be due the low dose of adjuvant that we used.

Clonidine due to its action on alpha 2 receptors causes a fall in the HR and BP. The degree of hypotension depends on the dose of clonidine used. ${ }^{6}$ Hemodynamic stability will be maintained with lower doses of clonidine. ${ }^{3}$ 
In the present study, there were no clinically significant variations in HR, BP and SPO2.There was a minimal fall in the BP from the basal values, noted in both the groups. But, defined hypotension was observed only in $3.3 \%$ patients in Group 1 and $6.7 \%$ of patients in Group 2. The results of our study are similar to that of Dobrydnjov et $\mathrm{al}^{3}$, where the incidence of hypotension was only $3.3 \%$ in their $30 \mathrm{mcg}$ Clonidine group.

Clonidine produces dose dependent sedation when used intrathecally. We did not observe deep sedation in any of our patients and there was no significant difference between the groups studied. Various authors in their studies observed that low dose of intrathecal clonidine produced an acceptable range of side effects. ${ }^{10}, 14$ In the 60 patients studied we noticed defined hypotension in one patient in Group 1 and two patients in Group 2. No other complications were noted.

CONCLUSION: Clonidine when used in the dosages of $0.5 \mathrm{mcg} / \mathrm{kg}$ and $1 \mathrm{mcg} / \mathrm{kg}$ intrathecally as an adjuvant to $0.5 \%$ hyperbaric Bupivacaine, prolonged the duration of action of Bupivacaine. With the doses and concentrations of drugs we used, we observed only a minimal fall in BP in both groups without significant complications. Pertaining to the duration of analgesia, $0.5 \%$ hyperbaric Bupivacaine with $1 \mathrm{mcg} / \mathrm{kg}$ of Clonidine produced statistically significant longer duration of analgesia compared to $0.5 \mathrm{mcg} / \mathrm{kg}$ of Clonidine. But clinically the difference was about 45 minutes only.

For lower limb surgeries like intramedullary nailing of tibia, the desired duration of analgesia can be achieved by using lower doses of Clonidine which inturn do not produce undesirable adverse effects. In this study, we observed that both the doses of Clonidine as an adjuvant to Bupivacaine produced good postoperative analgesia with very minimal side effects. Clinically no significant differences were found between the two groups, in respect to vital parameters and complications, hence $0.5 \mathrm{mcg} / \mathrm{kg}$ of clonidine maybe used as an adjuvant to Bupivacaine in tibial intarmedullary nailing as it is equally effective as $1 \mathrm{mcg} / \mathrm{kg}$ of clonidine.

\section{BIBLIOGRAPHY:}

1. Gautier, DeKock,VanStreenberge, Poth, Lahaye, Goffart, Fanared, et al. Intrathecal Ropivacaine for ambulatory surgery:A comparison between intrathecal Bupivacaine and intrathecal Ropivacaine for knee arthroscopy. Anaesthesiology 1999 Nov; 91(5):1239.

2. Kathirvel S, Sadhasivam S, Saxena A, Kannan TR, Ganjoo P. Effects of intrathecal Ketamine added to Bupivacaine for spinal anaesthetia. Anaesthetia 2000 Sep; 55(9):899-904.

3. Dobrydnjov I, Axelsson K, Thorn SE, Mathieson P, Klockhoff $\mathrm{H}$, Holmstroma B, etal. Clonidine combined with small dose Bupivacaine during spinal anaesthesia for inguinal hernioraphy: a randomized double blinded study. Anesth Anal 2003; 96:1496-503.
4. Dobrydnjov I, Samarutel J. Enhancement of intrathecal lidocaine by addition of local and systemic Clonidine. ActaAnaesthesiolScand 1999; 43:556-62.

5. Dobrydnjov I, Axelsson K, Samarutel J, Holmstrom B. Postoperative pain relief following intrathecal Bupivacaine combined with intrathecal or oral Clonidine. ActaAnaesthesiolScand 2002 Aug; 46(7):806-14.

6. Niemi L. Effects of intrathecal Clonidine on duration of Bupivacaine spinal anaesthesia, haemodynamics and postoperative analgesia in patients undergoing knee arthroscopy. ActaAnaesthesiolScand 1994 Oct; 38(7):724-8.

7. Ronald D Miller, "Miller's Anaesthesia", Churchill Livingstone Elsevier 7th Edition, 2009, 284-85.

8. Strebel S, Gurzeler JA, Schneider MC, Aeschbach A, Kindler CH. Small dose intrthecal Clonidine and isobaric Bupivacaine for orthpaedic surgery: A dose response study. AnesthAnalg 2004; 99:1231-8.

9. Van Tuijl I, Van Klei WA, Vander Werff DBM, Kalkman CJ. The effect of addition of intrathecal Clonidine to hyperbaric Bupivacaine on postoperative pain and morphine requirements after cessarian section: A randomized controlled trial. British journal of anaesthesia 2006; 97(3):365-70.

10. Sethi BS, Samuel M, Sreevastava D. Efficacy of Analgesic effects of low dose intrathecal Clonidine as adjuvant to Bupivacaine. Indian journal of Anaesthesia 2007; 51(5): 415-9.

11. Filos KS, Goudas LC, Patroni O, Polyzou V. Haemodynamic and analgesic profile after intrathecal Clonidine in humans: a dose response study. Anaesthesiology 1999; 91:388-96.

12. Kabaachi O, Ben Rajeb A, Mebazaa M, Safi H, JelelC,BenGhachemMet al Spinal anaesthesia in children:comparative study of hyperbaric bupivacaine with or without clonidine. AnnalesFrancaisesD'anesthesie et de Reanimation[2002, 21(8):617-621]

13. Kabaachi o, Zarghouni A, Ouezini R, Abdelaziz A, Chattaoui $\mathrm{O}$, Kokki $\mathrm{H}$. Clonidine $1 \mathrm{mcg} / \mathrm{kg}$ is a safe and effective adjuvant to plain bupivacaine in spinal anaesthesia in adolescents. Anaesthesia and analgesia 2007:105(2):516-19.

14. Saxena H , Singh S K, Ghildiyal S. Low dose intrathecal clonidine with bupivacaine improves onset and duration of block with hemodynamic stability.The Internet journal of Anesthesiology 2010;23:1-10

15. Grandhe RP, Wig J, Yaddanapudi LN. Evaluation of bupivacaine Clonidine combination for unilateral spinal anaesthesia in lower limb orthopedic surgery. J AnaesthClinPhamacol 2008; 24(2):155-58. 


\begin{tabular}{|c|c|c|c|}
\hline Variables & Group 1 & Group 2 & P value \\
\hline Age in years & $36.50 \pm 8.58$ & $37.53 \pm 9.29$ & 0.656 \\
\hline \multirow{2}{*}{ Gender distribution } & $\begin{array}{c}\text { Male: } 73.3 \% \\
\text { Female: } 26.7 \%\end{array}$ & $\begin{array}{c}\text { Male }: 70 \% \\
\text { Female: } 30 \%\end{array}$ & 0.774 \\
\hline ASA Grading & $\begin{array}{c}\text { ASA } 1: 76.7 \% \\
\text { ASA } 2: 23.3 \%\end{array}$ & $\begin{array}{c}\text { ASA } 1: 90 \% \\
\text { ASA 2: } 10 \%\end{array}$ & 0.166 \\
\hline Height (cms) & $162.53 \pm 4.65$ & $162.83 \pm 4.32$ & 0.797 \\
\hline Weight (kgs) & $62.47 \pm 7.78$ & $59.67 \pm 7.02$ & 0.149 \\
\hline Duration of surgery(mins) & $117.17 \pm 21.2$ & $117.50 \pm 16.12$ & 0.946 \\
\hline \multicolumn{4}{|c|}{ Table 1: Demographic data } \\
\hline
\end{tabular}

\begin{tabular}{|c|c|c|c|}
\hline Variables & Group 1 & Group 2 & P value \\
\hline Time to onset of sensory block & $2.17 \pm 0.36$ & $1.58 \pm 0.35$ & $<0.001^{* *}$ \\
\hline Time to reach highest sensory level & $9.40 \pm 1.07$ & $8.27 \pm 0.98$ & $<0.001^{* *}$ \\
\hline Duration of sensory block & $258.17 \pm 10.21$ & $289.33 \pm 15.24$ & $<0.001^{* *}$ \\
\hline Time to onset of motor block & $3.05 \pm 0.36$ & $2.33 \pm 0.50$ & $<0.001^{* *}$ \\
\hline Time for complete motor block & $7.53 \pm 0.86$ & $6.38 \pm 0.94$ & $<0.001^{* *}$ \\
\hline Duration of motor block & $228.83 \pm 10.96$ & $260.33 \pm 14.74$ & $<0.001^{* *}$ \\
\hline
\end{tabular}

\begin{tabular}{|c|c|}
\hline Groups studied & Duration of analgesia ( minutes) \\
\hline Group 1 & $306.33 \pm 18.24$ \\
\hline Group 2 & $351.00 \pm 15.83$ \\
\hline \multicolumn{2}{|c|}{ Table 3: Duration of analgesia } \\
\hline
\end{tabular}

$P$ value $<0.001^{* *}$

\begin{tabular}{|c|c|c|c|c|}
\hline \multirow{2}{*}{$\begin{array}{c}\text { Sedation } \\
\text { Score }\end{array}$} & \multicolumn{2}{|c|}{ Group 1 } & \multicolumn{2}{c|}{ Group 2 } \\
\cline { 2 - 5 } & No & $\mathbf{\%}$ & No & \% \\
\hline 1 & 10 & 33.3 & 9 & 30.0 \\
\hline 2 & 20 & 66.7 & 21 & 70.0 \\
\hline 3 & 0 & 0 & 0 & 0 \\
\hline 4 & 0 & 0 & 0 & 0 \\
\hline 5 & 0 & 0 & 0 & 0 \\
\hline Total & $\mathbf{3 0}$ & $\mathbf{1 0 0 . 0}$ & $\mathbf{3 0}$ & $\mathbf{1 0 0 . 0}$ \\
\hline \multicolumn{4}{|c|}{ Table 4: Sedation score } \\
\hline
\end{tabular}

$\mathrm{P}=0.781$, Not significant, Chi-Square test

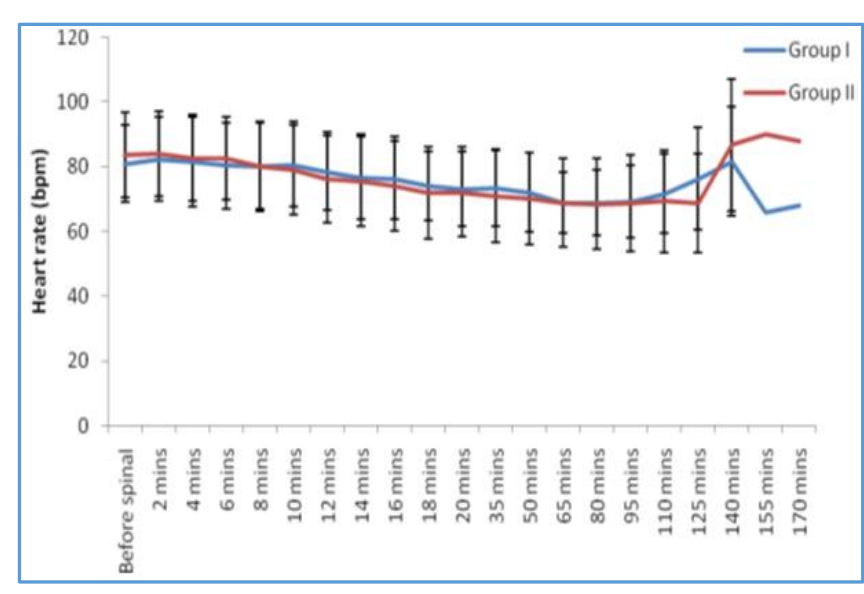

Fig. 2: Heart rate variations
Fig. 1: Comparison of MAP ( $\mathrm{mm} \mathrm{Hg}$ ) in two groups studied

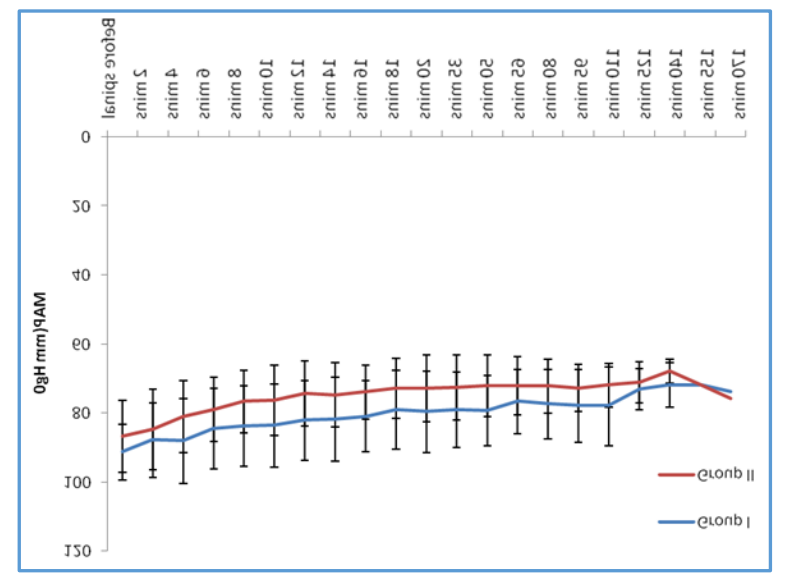

